\title{
COMPETITION BETWEEN LOLIUM PERENNE L. AND ANTHOXANTHUM ODORATUM L. AT TWO LEVELS OF PHOSPHATE AND POTASH
}

\author{
BY J. P. VAN DEN BERGH AND W.TH. ELBERSE
}

Institute for Biological and Chemical Research on Field Crops and Herbage, Wageningen, Holland

\section{INTRODUCTION}

In his study 'On competition' De Wit (1960) clearly demonstrated the great advantage of the replacement series in analysing competition phenomena (see also De Wit 1961). A replacement series may be defined by a series of mixtures in which one of the components is replaced by the other in such a way that

$$
c_{1} Z_{1}+c_{2} Z_{2}=m^{-1}
$$

where $c_{1}, c_{2}$ and $m$ are constants, and $Z_{1}$ and $Z_{2}$ are the quantities of the components (cf. Fig. 1).

On this basis the results of competition between two seed crops barley and oats were described by De Wit \& Ennik (1958); between two perennial grasses Phleum pratense L. and Anthoxanthum odoratum L. by Van den Bergh \& De Wit (1960) and between Lolium perenne $\mathbf{L}$. and Trifolium repens $\mathrm{L}$. by Ennik (1960). On the same basis De Wit \& Dijkshoorn (1961) described quantitatively the cation selectivity of Lolium perenne L., Dactylis glomerata $\mathbf{L}$. and Plantago lanceolata $\mathrm{L}$.

In a pot experiment described here the results of competition between an indicator for high fertility (Lolium perenne L.) and an indicator for low fertility (Anthoxanthum odoratum L.) at a high and a low PK-level of the soil are compared. In addition the results of a similar experiment are briefly discussed to confirm the results of the first one.

\section{METHOD}

Mitscherlich pots filled with a sandy soil were planted with clones of Lolium perenne and Anthoxanthum odoratum in different ratios. After a preliminary growing period the plants were kept at $2^{\circ} \mathrm{C}$ for 80 days, after which they were cut and the number of tillers per pot of each species was determined. This number is considered to be a measure of the abundance of the species. Next the plants were kept in a greenhouse during the months of August, September and October and cut once a month. The number of tillers was determined after each cut. In this way the changes with time in the ratios could be followed. Both grass species flowered profusely during the month of August.

The following nutrients were applied: 


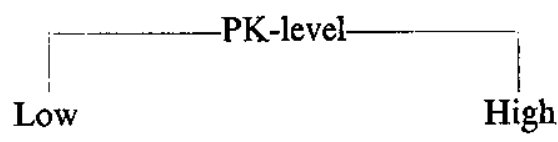

At the beginning of the experiment

(after the cold period)

After 1 month

After 2 months
Basic fertilizer ditto<smiles>[AlH2]</smiles>

20 cc $0.5 \mathrm{M} \mathrm{K}_{2} \mathrm{SO}_{4}$

$10 \mathrm{cc} 0.5 \mathrm{M} \mathrm{KH}_{2} \mathrm{PO}_{4}$

$20 \mathrm{cc} 1 \mathrm{M} \mathrm{NH} \mathrm{NO}_{3}$

$10 \mathrm{cc} 0.5 \mathrm{M} \mathrm{K}_{2} \mathrm{SO}_{4}$

$10 \mathrm{cc} 0.5 \mathrm{M} \mathrm{KH}_{2} \mathrm{PO}_{4}$

The same as at the beginning of the experiment

\section{RESULTS}

The line in Fig. 1, showing the relation between the values of $Z_{\mathrm{L}}$ and $Z_{\mathrm{A}}$, corresponds to the equation

$$
c_{\mathrm{L}} Z_{\mathrm{L}}+c_{\mathrm{A}} Z_{\mathrm{A}}=m^{-1}
$$

where $c_{\mathrm{L}}=1, c_{\mathrm{A}}=1 \cdot 71$ and $m^{-1}=282$, which holds for the series with low as well as with high fertility.

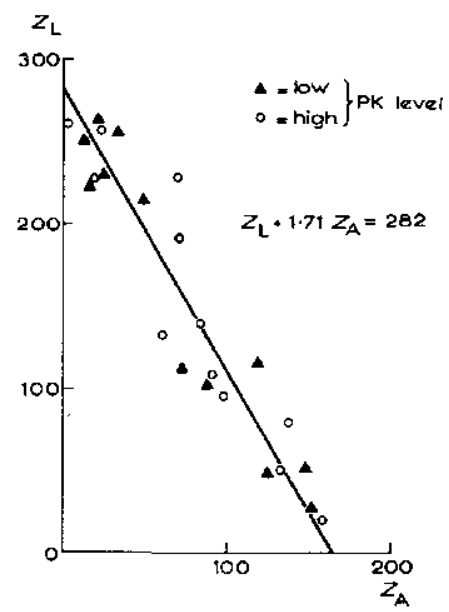

Fig. 1. The number of tillers of Anthoxanthum odoratum $\left(\boldsymbol{Z}_{\mathrm{A}}\right)$ Lolium perenne $\left(Z_{\mathbf{L}}\right)$ at the beginning of the experiment plotted on the abscissa and ordinate respectively.

The relative frequencies of Lolium and Anthoxanthum in any ratio at the beginning of the experiment are represented by:

$$
z_{\mathrm{L}}=\frac{Z_{\mathrm{L}}}{Z_{\mathrm{L}}+1 \cdot 71 Z_{\mathrm{A}}} \text { and } z_{\mathrm{A}}=\frac{1 \cdot 71 Z_{\mathrm{A}}}{Z_{\mathrm{L}}+1 \cdot 71 Z_{\mathrm{A}}}
$$

In Fig. 2 the values $O_{\mathrm{L}}$ and $O_{\mathrm{A}}$ for both series after 1,2 and 3 months of growth are 
plotted against $z_{\mathrm{A}}\left(=1-z_{\mathrm{L}}\right)$. The scattering of the points can be considerable because a point is based on a count in one pot only.
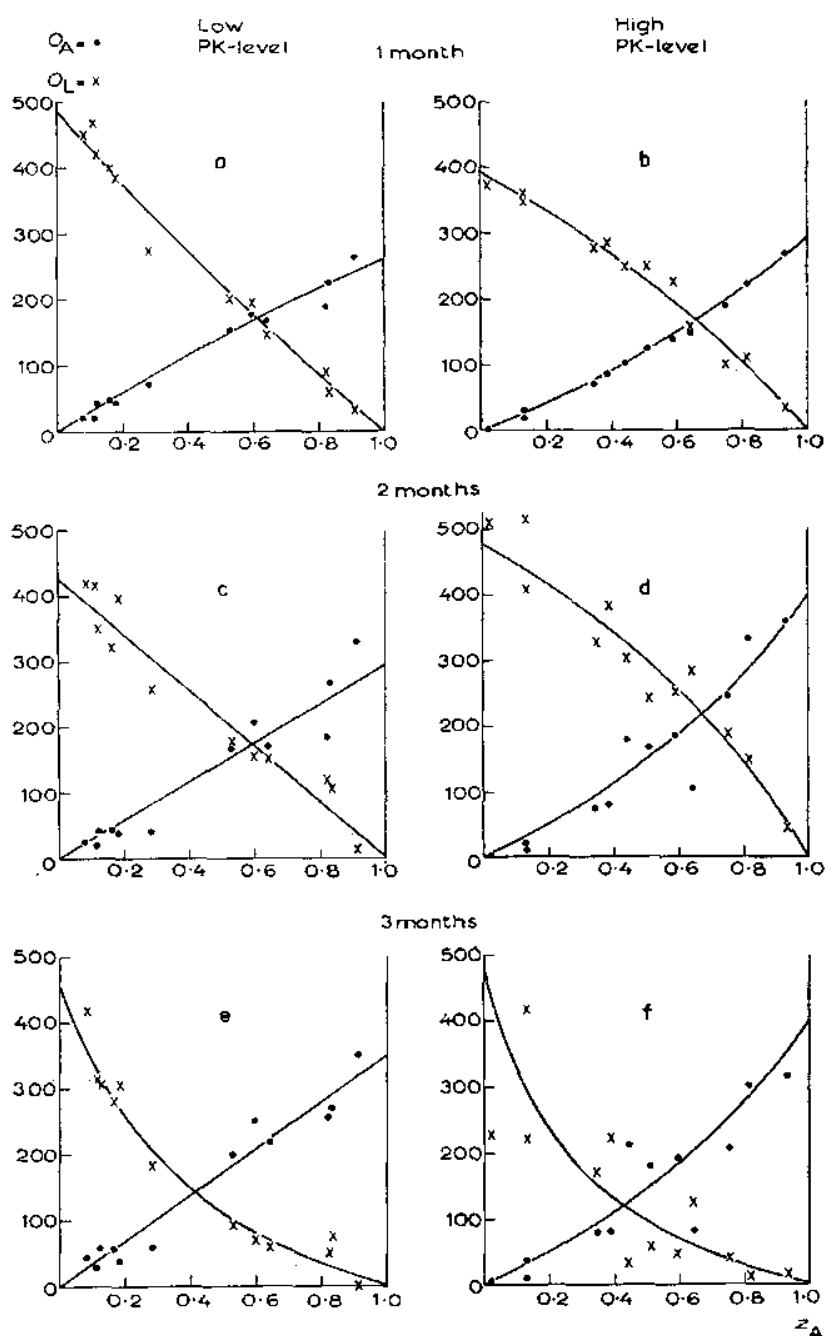

Fig. 2. The number of tillers of Anthoxanthum odoratum $\left(O_{\mathrm{A}}\right)$ and Lolium perenne $\left(O_{\mathrm{L}}\right)$ after subsequent monthly cuts plotted against the relative frequency of Anthoxanthum odoratum at the beginning of the experiment $\left(z_{\mathrm{A}}\right)$.

De Wit (1960) has shown that the smooth curves through the experimental points are given by:

$$
O_{\mathrm{L}}=\frac{k_{\mathrm{L} . \text { (A.e) } z_{\mathrm{L}}}}{\left(k_{\mathrm{L}(\mathrm{A} . \mathrm{e})}-1\right) z_{\mathrm{L}}+1} M_{\mathrm{L}} \quad O_{\mathrm{A}}=\frac{k_{\mathrm{A}(\mathrm{L} . \mathrm{e})} z_{\mathrm{A}}}{\left(k_{\mathrm{A}(\mathrm{L} . \mathrm{e})}-1\right) z_{\mathrm{A}}+1} M_{\mathrm{A}}
$$

where $k$ is the relative crowding coefficient of the species and $M$ is the number of tillers of the monocultures after 1 month of growth.

The product of the $k$-values after 1 and 2 months of growth for both series equals 1

G J.E. 
(Table 1), which means that these species influence each other only by crowding for the same space (De Wit 1960). In this case symbol e may be omitted, as it denotes the possibility of the species only partly crowding for the same space.

Table 1. The values of the relative crowding coefficients of Lolium with respect to Anthoxanthum $\left(k_{\mathrm{L}(\mathrm{A} . \mathrm{e})}\right)$ and of Anthoxanthum with respect to Lolium $\left(k_{\mathrm{A}(\mathrm{L} . \mathrm{e})}\right)$, the number of tillers of the monocultures of both species $\left(M_{\mathrm{L}}\right.$ and $M_{\mathrm{A}}$ resp.) and the values of the relative reproductive rate of Anthoxanthum with respect to Lolium ( $\left.a_{\mathrm{A} . \mathrm{L}}\right)$ after different growing periods with a low and a high PK-level of the soil

\begin{tabular}{|c|c|c|c|c|c|c|}
\hline & \multicolumn{3}{|c|}{ Low } & \multicolumn{3}{|c|}{ High } \\
\hline $\begin{array}{l}\text { 11me from the } \\
\text { beginning of the } \\
\text { experiment in } \\
\text { months }\end{array}$ & 1 & 2 & 3 & 1 & 2 & 3 \\
\hline${ }^{k} \mathrm{~L}(\mathrm{~A}, \mathrm{e})$ & 0.86 & 1.00 & 0.33 & 1.43 & 1.72 & 0.25 \\
\hline$k_{\mathrm{A}(\mathrm{L} . \mathrm{e})}$ & $1 \cdot 16$ & 1.00 & 1.00 & 0.70 & 0.58 & 0.58 \\
\hline $\begin{array}{c}{ }^{k} \mathbf{L}(\mathbf{A}, \mathbf{e}) \\
\times\end{array}$ & 1.0 & $1 \cdot 0$ & $0 \cdot 3$ & 1.0 & $1 \cdot 0$ & 0.15 \\
\hline $\begin{array}{l}k_{\mathrm{A}(\mathrm{L} . \mathrm{e})} \\
M_{\mathrm{L}} \\
M_{\mathrm{A}}\end{array}$ & $\begin{array}{l}485 \\
260\end{array}$ & $\begin{array}{l}425 \\
295\end{array}$ & $\begin{array}{l}450 \\
350\end{array}$ & $\begin{array}{l}390 \\
290\end{array}$ & $\begin{array}{l}475 \\
400\end{array}$ & $\begin{array}{l}475 \\
400\end{array}$ \\
\hline$a_{\text {A.I. }}$ & $1 \cdot 1$ & $1 \cdot 2$ & $\begin{array}{l}1 \cdot 3\left({ }^{z} \mathrm{z} \rightarrow 1\right) \\
4 \cdot 0\left({ }^{z} \mathrm{~A}_{\mathrm{A}} \rightarrow 1\right)\end{array}$ & 0.9 & 0.8 & $\begin{array}{l}0.8\left({ }^{2} \mathrm{z} \rightarrow 1\right) \\
5.8\left({ }^{2}{ }_{\mathrm{A}} \rightarrow 1\right)\end{array}$ \\
\hline
\end{tabular}

Since the species crowd for the same space in the first two months, the relative reproductive rate of Anthoxanthum with regard to Lolium may be represented by

$$
\alpha_{\mathrm{A} . \mathrm{L}}\left(=\frac{O_{\mathrm{A}} / Z_{\mathrm{A}}}{O_{\mathrm{L}} / Z_{\mathrm{L}}}=\frac{c_{\mathrm{A}}}{c_{\mathrm{L}}} k_{\mathrm{A} . \mathrm{L}} \frac{M_{\mathrm{A}}}{M_{\mathrm{L}}}\right.
$$

and consequently is independent of the composition of the mixture. This formula may be written also as follows: $\log \alpha_{\mathrm{A} . \mathrm{L}}=\log \left(O_{\mathrm{A}} / O_{\mathrm{L}}\right)-\log \left(Z_{\mathrm{A}} / Z_{\mathrm{L}}\right)$. By plotting $O_{\mathrm{A}} / O_{\mathrm{L}}$ and $Z_{\mathrm{A}} / Z_{\mathrm{L}}$ on logarithmic scales, the observations are scattered along straight lines parallel to the diagonal of the diagram (Fig. 3). These lines are calculated from the smoothed lines of Fig. $2 a-d$.

For the series with the low and high PK-level the relative reproductive rates after 1 month of growth equals 1.1 and 0.9 respectively and after 2 months 1.2 and 0.8 respectively (Table 1).

The product of the $k$-values 3 months after the beginning of the experiment is much smaller than $I$ in both series (Table 1). This proves that during the growth of the third cut the species affect each other in some other way than by crowding for space only (De Wit 1960). The relative reproductive rate of Anthoxanthum with regard to Lolium is now dependent on the composition of the mixture; consequently the observations (Fig. 3) lie around a line which forms an angle greater than $45^{\circ}$ with the horizontal axis. The limits of these relative reproductive rates are given by:

$$
\begin{aligned}
& z_{\mathrm{L} \rightarrow 1} \quad \alpha_{\mathrm{A} . \mathrm{L}}=\frac{k_{\mathrm{A}(\mathrm{L} . \mathrm{e})} c_{\mathrm{A}}}{c_{\mathrm{L}}} \times \frac{M_{\mathrm{A}}}{M_{\mathrm{L}}} \\
& z_{\mathrm{A} \rightarrow 1} \quad \alpha_{\mathrm{A} . \mathrm{L}}=\frac{c_{\mathrm{A}}}{k_{\mathrm{L}(\mathrm{A} . \mathrm{e}) c_{\mathrm{L}}}} \times \frac{M_{\mathrm{A}}}{M_{\mathrm{L}}}
\end{aligned}
$$


and are given in Table 1. The sigmoidal curves in Fig. 3 are calculated from the smoothed lines of Fig. $2 \mathrm{e}$ and $\mathrm{f}$.

The treatment of a similar experiment under controlled conditions is given in Fig. 4 and the results are shown in Fig. 5.

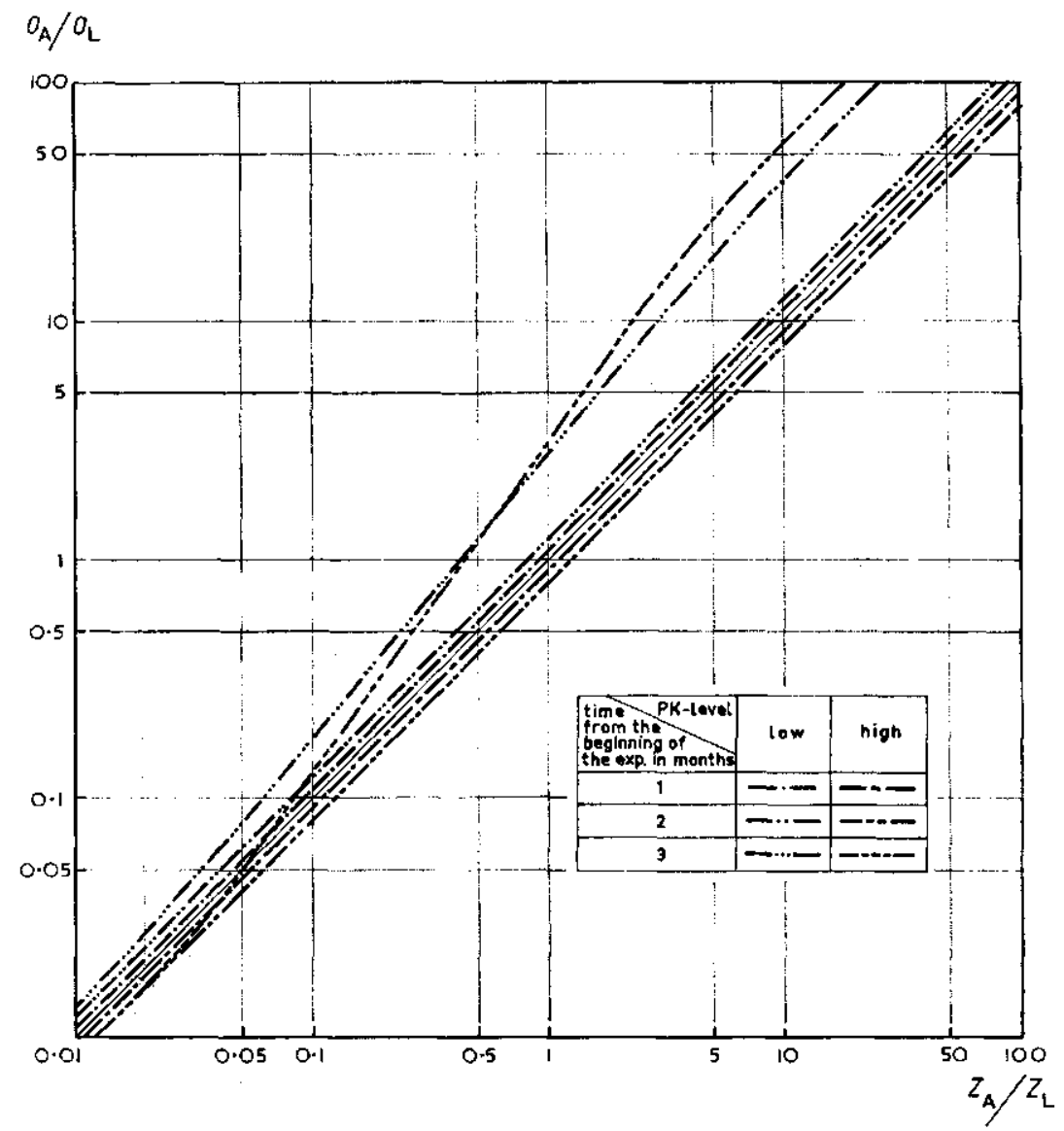

Fig. 3. The ratio of the number of tillers of Anthoxanthum odoratum and Lolium perenne after different growing periods $\left(O_{\mathrm{A}} / O_{\mathrm{L}}\right)$ and at the beginning of the experiment $\left(Z_{\mathrm{A}} / Z_{\mathrm{L}}\right)$ plotted on the abscissa and ordinate respectively. The lines are derived from the curves of Fig. 2.

As in the first experiment, the product of the $k$-values of the curves (Fig. 5a) is in the beginning equal to 1, but later this product becomes much smaller than 1 (Fig. 5b). In the final stage the curve of Lolium (dashed line in Fig. 5c) could not be smoothed with a constant $k$-value, because at values for $z_{\mathrm{A}}>0.5$ Lolium disappeared completely.

\section{DISCUSSION}

In considering Fig. 2 it is striking that during the first two months (Fig. 2a-d) the observations are either scattered along lines, which are curved to the same extent in opposite directions, or in the limiting case, along straight lines. This is expressed also in the products of the $k$-values of these lines which equals 1 (Table 1), the relative reproductive 
rate being constant (Fig. 3). It is true the points in Fig. $2 \mathrm{c}$ and $\mathrm{d}$ are scattered considerably, but this scattering is sufficiently balanced by the number of observations and the result of the experiment under controlled conditions (Fig. 5a).

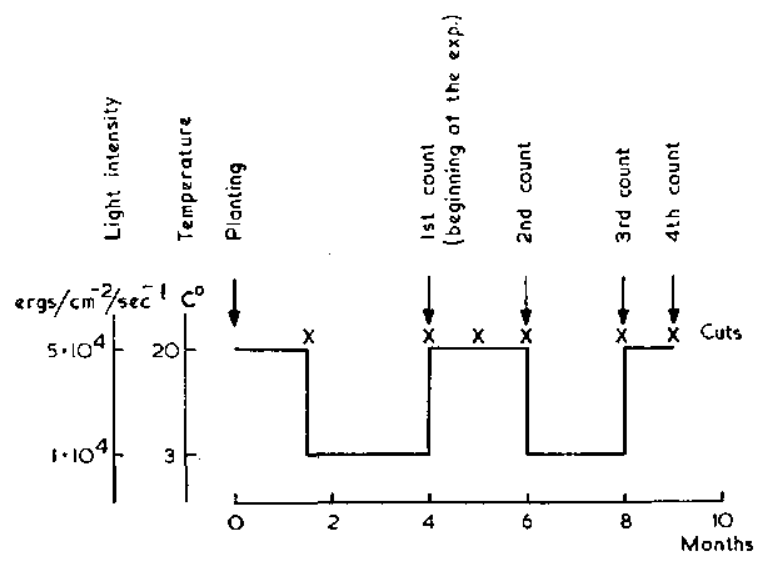

Fig. 4. The treatment of the experiment under controlled conditions during a 9-month period.
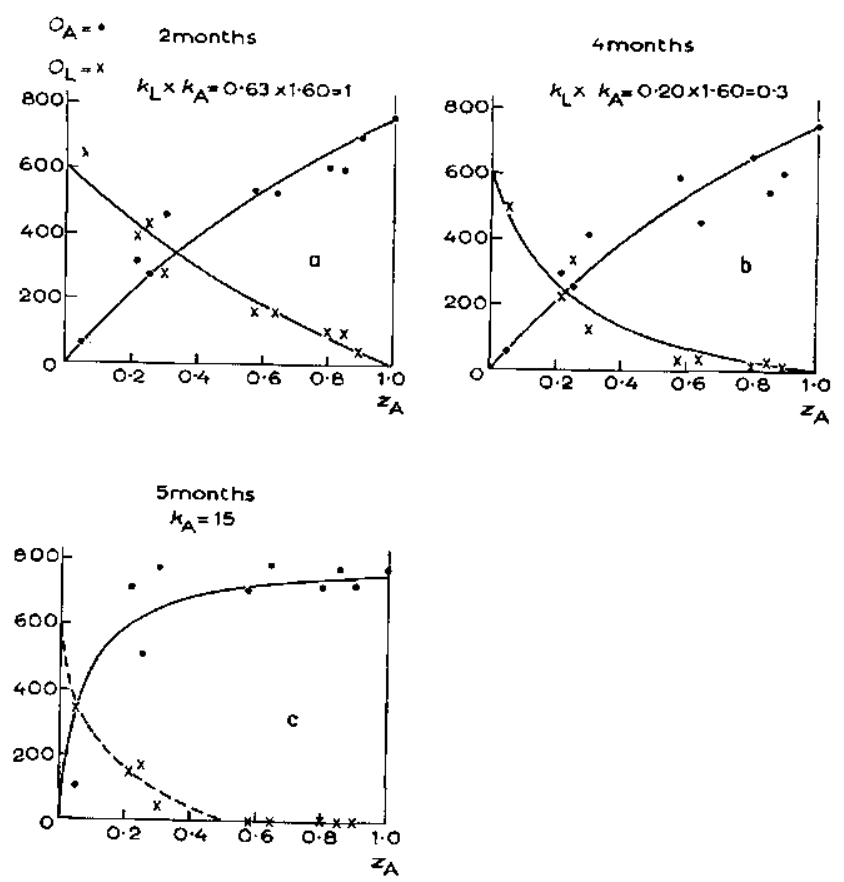

Fig. 5. The number of tillers of Anthoxanthum odoratum $\left(O_{\mathrm{A}}\right)$ and Lolium perenne $\left(O_{\mathrm{L}}\right)$ after different growing periods plotted against the relative frequency of Anthoxanthum odoratum at the beginning of the experiment under controlled conditions $\left(z_{\mathrm{A}}\right)$.

As mentioned before the species crowd for the same space in this period. Table 1 shows that the relative reproductive rate of Anthoxanthum with regard to Lolium at the low PK-level is larger than 1 and at the high PK-level smaller than 1. In the first case 
Anthoxanthum drives out Lolium and in the second case the reverse takes place. This corresponds to the results of De Vries et al. (1957), who found that the relative frequency of occurrence of Anthoxanthum is optimal and that of Lolium minimal in old permanent grasslands poor in phosphate and potash, whereas they found the reverse in old permanent grasslands rich in phosphate and potash.

Moreover it is evident from Fig. 2 and Table 1 that the calculated number of tillers of the monocultures of Anthoxanthum with the high PK-level in the corresponding months is larger than with the low PK-level. The fact that Lolium drives out Anthoxanthum at high PK-levels is not due to an adverse affect of the fertilizer on the growth of Anthoxanthum, but to the relative greater aggressiveness of Lolium under these circumstances. It must be observed, however, that there is no explanation for the high value of the monoculture of Lolium in Fig. $2 \mathrm{a}$ with regard to that in Fig. $2 \mathrm{~b}$.

Since $\log \left(O_{\mathrm{A}} / O_{\mathrm{L}}\right)=\log \left(Z_{\mathrm{A}} / Z_{\mathrm{L}}\right)+\log a_{\mathrm{A} . \mathrm{L}}$, the distance of the parallel lines to the diagonal in Fig. 3 is a measure for the rate at which one species drives out the other. From Fig. 3 it appears that in the series with a high as well as with a low PK-level, the distance of the line for 2 months is about twice of that of the line for 1 month. Consequently the flowering of both species during the first month has no other influence on the rate at which these species drive out each other than the vegetative growth in the second month.

If Fig. $2 \mathrm{e}$ and $\mathrm{f}$ are compared with Fig. $2 \mathrm{c}$ and $\mathrm{d}$ the sharp fall in the number of tillers of Lolium, which is dependent on the composition of the mixture, is obvious. The highly concave lines for Lolium are not compensated by highly convex lines for Anthoxanthum, which means that the species affect each other in some other way than by crowding for space only (De Wit 1960). In contrast to preceding cases (Ennik 1960, Van den Bergh \& De Wit 1960) in which the products of the $k$-values are larger than 1 , in this case this value is smaller than 1 . In these preceding cases, space is explored to a greater extent in the mixed cultures than in monocultures, while in the latter case a mixed culture is disadvantageous (De Wit 1960).

After 3 months the tillers of Lolium (especially those in pots with much Anthoxanthum) show symptoms which are attributed to a virus. It should be noticed that poisonous excretions (for instance coumarin) could not be the cause of these symptoms, since a monoculture of Lolium growing in the same room as Anthoxanthum showed exactly the same picture. Evidently this virus, which is carried by Anthoxanthum does not injure this grass, but may infect Lolium severely. Possibly Anthoxanthum is not only a symptomless carrier of the yellow-dwarf virus (Oswald \& Houston 1953) but is also host of other viruses.

The infection of Lolium will be more severe as the contact with Anthoxanthum becomes more intensive, e.g. in the pots with the high PK-level where the growth of tillers is most dense. This might be the reason why Lolium receded much more at the high PK-level than at the low one (compare Fig. $2 \mathrm{c}$ with $2 \mathrm{e}$ and $2 \mathrm{~d}$ with $2 \mathrm{f}$ ). The small difference between the shape of the lines of Anthoxanthum after 3 months and after 2 months may be attributed to the rather sudden outbreak of the disease. In the second experiment which is continued for a further growing period after the appearance of the disease, Anthoxanthum occupied the space which became available, so that the line of Anthoxanthum becomes very convex (Fig. $5 \mathrm{c}$ ).

Many competition phenomena which are supposed to be caused by poisonous excretions may be due to a similar process.

If the disease infects Lolium gradually, there will be hardly any empty space caused by 
the retreat of Lolium, since Anthoxanthum will occupy this space immediately. This implies a product of the $k$-values equal to 1 . Obviously with the mathematical presentation employed here we can not distinguish this case from crowding for space only.

In Fig. 3 the sigmoidal-curves reflect the dependence of the relative reproductive rate after 3 months on the composition of the mixture. The curve of the high PK-level intersects the diagonal at the point $(0.05 ; 0.05)$, that is to say at values of $Z_{\mathrm{A}} / Z_{\mathrm{L}}$ ( = $\left.O_{\mathrm{A}} / O_{\mathrm{L}}\right)<0.05$ Lolium drives out Anthoxanthum, whereas at values of $Z_{\mathrm{A}} / Z_{\mathrm{I}_{\mathrm{L}}}\left(=O_{\mathrm{A}} / O_{\mathrm{L}}\right)$ $>0.05$ the reverse takes place. Considering the rapid occupation by Anthoxanthum of the space which became available in the second experiment (Fig. 5c), it is to be expected that the entire sigmoidal-curve will lie far above the diagonal after a fourth month. This means that Lolium will be driven out completely by Anthoxanthum at an increasing rate.

\section{ACKNOWLEDGMENT}

It is a particular pleasure to acknowledge all the help we have received in so many ways from Dr ir. C. T. De Wit.

\section{SUMMARY}

With a pot experiment competition has been studied between an indicator for high fertility (Lolium perenne L.) and an indicator for low fertility (Anthoxanthum odoratum L.) at two PK-levels of the soil. Clones of each of the species were planted in different ratios making a replacement series. As a measure of the abundance of a species the number of tillers in the turf was taken. The mathematical treatment of the observations, made once a month after each cut, follows a method of De Wit (1960).

The results support the following conclusions:

1. During the first 2 months of the experiment the species influenced each other only by crowding for the same space. (The relative reproductive rate $\alpha$ is independent of the composition of the mixture.)

2. With the series at the high PK-level Lolium drove out Anthoxanthum and with the series at the low PK-level the reverse took place.

3. The rate at which these species drove out each other in the first month is as big as in the second month, notwithstanding the profuse flowering of both species during the first month.

4. During the third month the species affected each other in some other way than by crowding for space only ( $\alpha$ is dependent on the composition of the mixture). It is evident that Anthoxanthum carried a virus which is not harmful to this grass, but which severely infected the clone of Lolium in use. Consequently Lolium will be completely driven out by Anthoxanthum at an increased rate.

\section{REFERENCES}

De Vries, D. M., Kruijne, A. A. \& Mooi, H. (1957). Frequency of occurrence of herbage plants and their indication of environmental conditions (in Dutch with summary in English). Jaarb. Inst. Biol. Scheik. Onderz. Wageningen, 183-91.

De Wit, C. T. (1960). On competition. Versl. landbouw. $k$. Onderz. The Hague, 66 (8), 1-82.

De Wit, C. T. (1961). Space relationships within populations of one or more species. Pp. 314-29 in Mechanisms in biological competition (ed. F. L. Milthorpe). Soc. exp. Biol. Symp. 15.

De Wit, C. T. \& Dijkshoorn, W. (1961). Competitive uptake of cations by growing pasture plants (in manuscript). 
De Wit, C. T. \& Ennik, G. C. (1958). On competition (in Dutch with summary in English). Jaarb. Inst. Biol. Scheik. Onderz. Wageningen, 59-73.

Ennik, G. C. (1960). The competition between white clover and perennial rye-grass with differences in light intensity and moisture supply (in Dutch with summary in English). Jaarb. Inst. Biol. Scheik. Onderz. Wageningen, 37-50.

Oswald, J. W. \& Houston, B. R. (1953). Host range and epiphytology of the cereal yellow dwarf disease. Phytopathology, 43, 309-13.

Van den Bergh, J. P. \& De Wit, C. T. (1960). Competition between timothy grass (Phleum pratense L.) and sweet vernal-grass (Anthoxanthum odoratum L.) (in Dutch with summary in English). Jaarb. Inst. Biol. Scheik. Onderz. Wageningen, 155-65.

(Received 5 April 1961) 